\title{
Quality Management of Organic Ready-To-Eat Vegetable, Matar Paneer (Green Peas with Cheese) \\ Mohammad H Rahman*
}

Department of Organic Agricultural Sciences, Kassel University, Hesse, Germany

\begin{abstract}
Ready-to-eat foods are opening new window in world scenario as far as concerned taste, safety and nutrition. Ready to eat packaged food industry is growing at the rate $20 \%$ per annum, it shows the popularity and consumption and acceptance of ready to eat foods. Matar Paneer is nutritious ready to eat vegetable (food) with high quality, taste and flavour. It is a South Asian food, which contain curried green pea and cottage cheese cooked to perfection in mild sauce. The quality, taste and flavour of ready to eat vegetables remains good as fresh up to expiry date. Good manufacturing practices are very crucial in organic green pea's production. This food meet the consumer's specific expectations like convenience, nutritionally adequate, tasty, microbial safe, colour, flavour, organic and with time saving and easy to use.
\end{abstract}

Keywords: Ready-to-eat food; Quality; Consumer demand; Good manufacturing practice; Nutritious

\section{Introduction}

\section{Ready-to-eat foods}

Ready-to-eat foods are becoming popular in all over the world during last few years. It is one kind of food products which does not need processing on the part of consumer. Changing socio-economic status, life has become very fast. Ready-to-eat foods are consumed in short length of time with the development in packaging technology. It is tasty and delicious. It is now possible to produce commercially and to extend the shelf life up to few years. The developments in food technology and packaging technology have made it possible to increase the shelf life of these products [1].

\section{Matar paneer}

It is ready-to-eat South Asian food, which contain curried green pea and cottage cheese cooked to perfection in mild sauce.

Ingredients: Green Peas (35\%), Tomato, Indian Cottage Cheese (Milk or milk solids, citric acid, salt) (20\%), Onion, Cottonseed oil, Ginger fresh, Garlic fresh, Salt, Melon seeds, Green chilli, Chilli powder, Cashew nuts, Spices (Black pepper, Cinnamon, Clove, Coriander, Cardamom, Chilies, Cumin, Poppy seeds, Nutmeg, Bay leaf), Coriander powder, Turmeric powder, Dried fenugreek leaf.

In production of organic Matar Paneer, it is crucial to use organic raw materials. Matar (green pea) is the main ingredient of product which has $35 \%$ value in total. Paneer (Cheese) is the second main ingredient followed by green pea. Green pea and cheese must be organic for to produce organic Matar Paneer ready-to-eat vegetable. With concern to quality management basic hygiene in all stages of production will leads to less hazards, great food safety and less product failure. Retorting of cooked vegetable (Matar Paneer) after pouch filling, is important critical control point where killing of all microorganisms is take place and which extend the shelf life of product up to more than one year. With a view to ready-to-eat market demand and growth, processed food market in Bangladesh accounts for more than 30\% that is 4 to 5 billion US \$. Ready to eat packaged industry is growing at the rate $15 \%$ per annum. Ready to eat food market is developing specifically in UK, USA, Canada, Gulf and South Asian countries with the growth rate of over $150 \%$ per annum [2].

\section{Nutritional content}

Green pea: Scientific name-Pisum sativum. It is high nutritious leguminous vegetables and rich in health benefiting phyto-nutrients, minerals, vitamins and anti-oxidants. It is an excellent source of vitamin $\mathrm{K}$ which is needed for blood clotting. It is also excellent source of vitamin A (provide $765 \mathrm{IU}$ or $25.5 \%$ of RDA per $100 \mathrm{~g}$ ) in the form of beta-carotene (Table 1).

It is an excellent source of folic acid. Like most vegetables, green pea is low in calories, fat free and good source of fibre. It is also good in essential vitamins B-complex like pantothenic acid, niacin, thiamin and pyridoxine. Moreover, they are rich sources of many minerals such as $\mathrm{Ca}, \mathrm{Ir}, \mathrm{Cu}, \mathrm{Zn}$, and $\mathrm{Mn}$. Matar Paneer: Matar paneer is an excellent source of certain nutrients. The nutrient content of $280 \mathrm{gms}$ pack is mentioned in Table 2.

\section{Why ready-to-eat vegetables?}

Ready-to-eat foods are fast growing global population foods and its popularity growing among the consumer. Consumers are getting more health conscious and organic loving. Quality, taste and flavor of these foods remain as good as fresh up to the expiry date. Usually, the shelf lives of the RTE foods are more than the other foods. With change in lifestyle, nuclear families, working couples, more and more people are opting for ready to eat food in a quagmire way. Consumer can enjoy the food during off season and it is very hygienic. Ready to eat foods are very easy to use; when need to eat, the food item pouch is either put in microwave oven to warm it or keep in heated water for few minutes and then serve to eat.

\section{Quality management in different processing stages/farm to fork}

Matar paneer processing goes through certain operation stages, through which proper quality management is essential to good quality

*Corresponding author: Mohammad $\mathrm{H}$ Rahman, Department of Organic Agricultural Sciences, Kassel University, Hesse, Germany, Tel: +49-5618040; E-mail: tuki.st07@gmail.com

Received June 20, 2016; Accepted July 08, 2016; Published July 15, 2016

Citation: Rahman MH (2016) Quality Management of Organic Ready-To-Eat Vegetable, Matar Paneer (Green Peas with Cheese).J Food Process Technol 7: 606. doi:10.4172/2157-7110.1000606

Copyright: (C) 2016 Rahman MH,This is an open-access article distributed under the terms of the Creative Commons Attribution License, which permits unrestricted use, distribution, and reproduction in any medium, provided the original author and source are credited. 


\begin{tabular}{|c|c|c|}
\hline \multicolumn{3}{|c|}{ Green peas (Pisum sativum), fresh, raw, Nutrition value per $100 \mathrm{~g}$} \\
\hline Principle & Nutrient Value & $\begin{array}{c}\text { Percentage of } \\
\text { RDA }\end{array}$ \\
\hline Energy & $81 \mathrm{Kcal}$ & $4 \%$ \\
\hline Carbohydrates & $14.45 \mathrm{~g}$ & $11 \%$ \\
\hline Protein & $5.42 \mathrm{~g}$ & $10 \%$ \\
\hline Total Fat & $0.40 \mathrm{~g}$ & $2 \%$ \\
\hline Cholesterol & $0 \mathrm{mg}$ & $0 \%$ \\
\hline Dietary Fiber & $5.1 \mathrm{~g}$ & $13 \%$ \\
\hline \multicolumn{3}{|l|}{ Vitamins } \\
\hline Folates & $65 \mu \mathrm{g}$ & $16 \%$ \\
\hline Niacin & $2.090 \mathrm{mg}$ & $13 \%$ \\
\hline Pantothenic acid & $0.104 \mathrm{mg}$ & $2 \%$ \\
\hline Pyridoxine & $0.169 \mathrm{mg}$ & $13 \%$ \\
\hline Riboflavin & $0.132 \mathrm{mg}$ & $10 \%$ \\
\hline Thiamin & $0.266 \mathrm{mg}$ & $22 \%$ \\
\hline Vitamin A & $765 \mathrm{IU}$ & $25.50 \%$ \\
\hline Vitamin C & $40 \mathrm{mg}$ & $67 \%$ \\
\hline Vitamin E & $0.13 \mathrm{mg}$ & $1 \%$ \\
\hline Vitamin $\mathrm{K}$ & $24.8 \mu \mathrm{g}$ & $21 \%$ \\
\hline \multicolumn{3}{|l|}{ Electrolytes } \\
\hline Sodium & $5 \mathrm{mg}$ & $<1 \%$ \\
\hline Potassium & $244 \mathrm{mg}$ & $5 \%$ \\
\hline \multicolumn{3}{|l|}{ Minerals } \\
\hline Calcium & $25 \mathrm{mg}$ & $2.50 \%$ \\
\hline Copper & $0.176 \mathrm{mg}$ & $20 \%$ \\
\hline Iron & $1.47 \mathrm{mg}$ & $18 \%$ \\
\hline Magnesium & $33 \mathrm{mg}$ & $8 \%$ \\
\hline Manganese & $0.410 \mathrm{mg}$ & $18 \%$ \\
\hline Selenium & $1.8 \mu \mathrm{g}$ & $3 \%$ \\
\hline Zinc & $1.24 \mathrm{mg}$ & $11 \%$ \\
\hline
\end{tabular}

Table 1: Green peas fresh, raw, nutrition value per $100 \mathrm{~g}$ [10]

\begin{tabular}{|c|c|c|c|c|c|c|c|}
\hline \multicolumn{2}{|c|}{ Nutrition Facts } & \multicolumn{2}{|c|}{ Amount/Serving } & $\%$ DV & \multicolumn{2}{c|}{ Amount/Serving } & $\%$ DV \\
\hline $\begin{array}{c}\text { Serve } \\
\text { Size }\end{array}$ & $1 / 2$ pack & Total Fat & $12 \mathrm{~g}$ & $20 \%$ & $\begin{array}{c}\text { Total } \\
\text { Carbohydrate }\end{array}$ & $15 \mathrm{~g}$ & $5 \%$ \\
\hline Servings & 2 & Sat. Fat & $5 \mathrm{~g}$ & $25 \%$ & Fibre & $3 \mathrm{~g}$ & $12 \%$ \\
\hline Calories & 200 & Cholesterol & $15 \mathrm{mg}$ & $5 \%$ & Sugars & $0 \mathrm{~g}$ & - \\
\hline Fat Cal. & 110 & Sodium & $560 \mathrm{mg}$ & $23 \%$ & Proteins & $9 \mathrm{~g}$ & - \\
\hline
\end{tabular}

Vitamin A: $2 \%$; Vitamin C: $10 \%$; Calcium: $10 \%$; Iron $6 \%$

Percent Daily Values (DV) is based on 2000 calories diet.

Table 2: Nutrient content of 280 gm pack.

of product. From farm to consumer there is different factor which affects the quality of product. On each stage of processing application of quality management technology is essential to avoid further losses. Preharvest, post-harvest technology play crucial role to manage quality of product [3]. To produce organic product all raw materials should be organic and should be no use of any chemical preservatives.

\section{Organic green pea cultivation}

Organic cultivation will leads to the organic production of green pea. Following is some important points which are require focusing during organic green pea cultivation.

Soil health: Healthy soil is very important for organic green pea farming. Kind of cover crops, compost, or manure creates a soil that is biologically full of life with good structure and capacity to hold nutrients and water. Decomposing plant materials will activate a different pool of microbes, including those that break down organic matter into plantavailable nutrients, as well as others that compete with plant pathogens on the soil and on the root surface [4].
Weed management: Weed management includes crop rotation, cover cropping, cultivation, and planting design is one of the biggest challenges on organic green peas farming [5].

Recommended varieties: Variety selection is important both for the horticultural characteristics specified by the processor and the pest resistance profile that will be the foundation of a pest management program. Green peas varieties are illustrious by leaf texture and range from flat (smooth) skin to savoy skin. Depending on the time of planting, other characteristics are important to consider when choosing peas varieties such as bolting tolerance, growth rate and disease resistance and growth habit. A certified organic farmer is required to plant certified organic seed.

Planting: Green pea seed germinates in relatively cool soil (as low as $40^{\circ} \mathrm{F}$ ). Planting can begin in late March or early April and continue until May 20th-30th. Early plantings usually yield more than later plantings as they grown-up during the cooler part of summer. It grows rapidly. Somewhat thinner stands will help control foliar diseases by providing better air circulation. Sow seeds to the correct spacing because thinning is not recommended [5].

Crop and soil nutrient management: Total crop nutrient needs: research indicate that an average spinach crop requires $50 \mathrm{lbs}$. of available nitrogen $(\mathrm{N}), 100 \mathrm{lbs}$. of phosphorus (P), and $120 \mathrm{lbs}$. of potassium (K) per acre to support a medium to high yield. More nitrogen may be required for a processing crop than a fresh market crop. Soil pH is very crucial for green pea crops (Table 3 ). The average $\mathrm{pH}$ of 6.5 is requiring for better growth of green peas. The field will be planting a $\mathrm{pH}$ of 6.5 , and planting into a winter-killed oat residue that was seeded in early September after you incorporated 2000 gallons of liquid dairy manure [5].

Using organic pesticides: In some cases organically approved pesticides, which include repellents are a necessary option. Calibrating sprayers is especially very important when using organic pesticides since their effectiveness is sometimes limited. For this reason, they tend to require the best spraying conditions to be effective. Read the label carefully to be familiar with the unique requirements of some products, especially those with live biological organisms as their active ingredient (e.g. Contans). The active ingredients of some biological pesticides (e.g. Serende and Sonata) are actually metabolic by-product of the organism. The use of pheromone traps or other monitoring prediction techniques can provide an early warning for pest problems, and help effectively focus scouting efforts [5]. Integrated Pest Management (IPM) is a key to sustainable pest control. The objective is to adopt cultural, biological, mechanical, physical and other less hazardous strategies to minimize the use of pesticides.

Harvesting: Most varieties reach fresh market harvest stage in 50 to 60 days under good growing conditions, but 50 to 70 days may be required for early spring plantings. Green pea for the processing market can take longer to reach optimum size and texture. Insects and weeds are considered contaminants at harvest. Handle carefully as green peas is very vulnerable to bruising. Whole pea pods serve as controlled atmospheric storages that maintain quality for about one week at $32^{\circ} \mathrm{F}$

\begin{tabular}{|c|c|c|c|c|c|c|c|}
\hline & N Level & \multicolumn{3}{|c|}{ Soil P Level } & \multicolumn{3}{|c|}{ Soil K Level } \\
\hline $\begin{array}{c}\text { Level shown } \\
\text { in soil }\end{array}$ & $\begin{array}{c}\text { Not } \\
\text { Available }\end{array}$ & Low & Med. & High & Low & Med. & High \\
\hline & $\mathrm{N} \mathrm{lbs} / \mathrm{A}$ & \multicolumn{2}{|c|}{$\mathrm{P}_{2} \mathrm{O}_{5}$ lbs/A } & \multicolumn{3}{|c|}{$\mathrm{P}_{2} \mathrm{O}_{5}$ lbs/A } \\
\hline $\begin{array}{c}\text { Total nutrient } \\
\text { Requirement }\end{array}$ & 60 & 100 & 75 & 50 & 120 & 80 & 40 \\
\hline
\end{tabular}

Table 3: Recommended amount of $P$ and $K$ for green pea based on soil test. 
and $90 \%-95 \%$ relative humidity. Once shelled, quality deteriorates rapidly. That's why, processing green pea, which are shelled in the field, must be transported quickly to the processing service.

\section{Transportation of green pea}

Transportation is one of the most critical due to high product loss as result of poor transport conditions, rough handling, and delays. To avoid these losses appropriate techniques are using to transportation of green peas like cold storage, evaporative cooling (use of wet cloth). In addition, ice topping reduces temperature to $20^{\circ} \mathrm{C}$ to $25^{\circ} \mathrm{C}$ from $35^{\circ} \mathrm{C}$ to $40^{\circ} \mathrm{C}$ during transport and storage. Other measures to reduce the certain losses are immobilized attacks of packages by bracing and/or strapping; careful handling of packages; air suspension of trucks to reduce road shock and vibration [6].

\section{Storage}

Green pea is a perishable product, but if picked early in the day, cooled rapidly after harvest, and topped with ice it can be stored for 14 to 20 days. Cooling will reduce the naturally high respiration rate of green pea. Forced air or vacuum cooling provides a quick reduction in temperature. The use of top ice acts to supply moisture and remove heat. Always use ice made from potable water. Air flow through and around boxes is also essential. Optimal storage conditions are $32^{\circ} \mathrm{F}$ with 95 to 100 percent relative humidity. Green peas will yellow if transported with high ethylene producing crops such as apples, melons or tomatoes.

\section{Paneer (cottage cheese) quality parameter}

For production of organic Matar Paneer it is essential to use organically produced paneer which have good quality. Paneer is a popular south Asian dairy product obtained by acid coagulation of whole milk and ensuing drainage of whey and is widely used for culinary purpose. To understand the quality attributes the final product specifications should be acknowledged as-

\section{Protein: $17.5 \%$ to $25 \%$}

\section{Fat: $20 \%$ to $25 \%$}

\section{Carbohydrates: $2 \%$}

\section{Minerals: $1.5 \%$}

Moisture: $40 \%$ to $50 \%$. The storage temperature must be $-12^{\circ} \mathrm{C}$ to $-14^{\circ} \mathrm{C}[7]$.

\section{Processing of green pea cheese/matar paneer}

Cleaning, sorting of green pea: Cleaning and sorting of green peas are essential to avoid contamination of microbes. In sorting must consider some specific attributes of green peas which are important in case of processing point of view. Always look for, leaves that are fresh, young, tender and mostly whole (not torn). Look for dark green and lighter green stems. Must be avoiding pea with thick, yellowish-green colour, softness or a wilted condition. These are all signs of decay. Should be cut root part to remove dirt and unwanted part of peas.

Washing: Washing can helps to remove the dirt of green peas. First of all, drop the green peas into a large bowl of lukewarm water, and then stir them gently with the hands. After then, the green peas should be lift out to let the sand and grit settle. Next, empty and refill the bowl with clean water and wash the green peas again. It should be repeated until there is no sand or grit on the bottom of the bowl and the green peas is cleaned.
Blanching/pre-cooking: Blanching or pre-cooking $\mathrm{s}$ done by immersing green peas in water at temperature of $90^{\circ} \mathrm{C}$ to $95^{\circ} \mathrm{C}$. Exposing it to steam is also possible. The result is that green peas become somewhat soft and enzymes are inactivated. Pea's skin becomes shrinking in this process and some of the micro-organism dies. Blanching is done before a product is dried in order to prevent unwanted colour and odour changes and an excessive loss of vitamins. Add little amount of sugar to kill the bitterness. The disadvantage of this blanching method is that many vitamins are lost in the hot water. Steaming is therefore a better alternative. Only a small amount of water has to be added to pan and brought to the boil [8].

Cooking: After blanching/pre-cooking it should be cooked in steam jacketed kettle. Simultaneously curry is prepared with ingredients like Tomato, Onion, Cottonseed oil, Green chilli, Milk cream, Ginger fresh, Sugar, Salt, Corn flour, Cumin, Turmeric powder and Water and both are mixed homogenously. Steam jacketed kettles are convenient in handling and easy to cook with less risk averse. To maintain good texture and taste of paneer, it should be add during the pouch filling because if it adds during cooking paneer will reduce its texture while cooking. The yield is $120 \%$ due to addition of many other ingredients and water. Cooking temperature should be kept in $75^{\circ} \mathrm{C}$ to $80^{\circ} \mathrm{C}$ or $90^{\circ} \mathrm{C}$.

Quality checking: As concern to quality parameter, should be placed in acknowledged to maintain product with $4.5-5.0 \mathrm{pH}$, low in acidity. To maintain several sensory parameters such as good flavour, taste, colour and texture are very important at consumer's point of view. The most important is microbial checking. Foods may contain a variety of microorganisms, many of which are harmless and many more are harmful and if consumed those food can cause illness. To get good food safety should be check the availability of microorganisms like Escherichia coli, Staphylococcus aurous etc. Nutritional content checking is important after cooking to meet the specification standard. If there will be lack of any nutrient then must be take into consideration in next lot of production.

Pouch filling: Pouch filling is to be carried out after cooking of green pea. The filling is usually carried out by machine. Machine helps to make process fast and also reduces contamination of some microorganisms. The pipe is connected from cooking kettles to the machine by which the sauce is passing to machine. The machine is automatic and it fills the required amount (set by manually) of sauce in pouch. Paneer should be adding homogeneously from other side of machine. Paneer directly will be getting placed in pouch and finally the mouth of pouch becomes closed. There are different types of filling machines are available in market. Choosing of machine might be depending on the size of company.

Retort pack: Retort packaging materials are specified thermal processing in a closed retort at temperature over $100^{\circ} \mathrm{C}$. Retortable packages maintain green pea's integrity as well as their required barrier properties for the designated product during handling, thermal processing and subsequent handling and transport abuse. This pouch also acts as barrier against such effect as light, moisture, oxygen and microbial penetration etc. Retort pouch is made from multilayer plastic films with aluminum foil as one of the layers. Their most key feature is that, unlike usual flexible pouches they are made of heat resistant plastics, thus making them suitable for processing in retorts at temperature of around $121^{\circ} \mathrm{C}$ normally encountered in thermal sterilization of food. Besides, retort pouches possess toughness and puncture resistance normally required for any flexible packaging to be machinable in pouch making and packaging operations and also withstand the rigors of handling and distribution. 
Typical structure used for retort pouch: The structure of the reportable pouch, in general use today, is a 3-ply laminate composed of $16 \mu$ polyester film, adhesive laminated to $9 \mu$ aluminum foil, which is either laminated $60 \mu \mathrm{CCP}$ or is extrusion coated with $60 \mu \mathrm{CCP}$.

The basic requirements of retort pouch film are as follows:

I. Low gas (oxygen) permeability.

II. Low vapor transmission rate.

III. Resistance to temperature from below $0^{\circ} \mathrm{C}$ to at least $121^{\circ} \mathrm{C}$ to cover possible storage condition exposures and the minimum sterilization level for low acid products.

IV. Inertness in terms of resistance to penetration by food components and low migration of film components in conformance with food and drug regulation.

V. Good ageing properties.

VI. Physical strength to resist any handling abuse during manufacturing and during distribution cycle.

Air removal: Removal of air from the filled pouch is done to remove the bulk of air from retort pouches before they are sealed. Removal of air from the filled pouch is normally effected on an automatic line and is necessary for several reasons like:

a. To ensure product stability.

b. To avoid pouch bursting during retorting.

c. To assist uniform heat transfer.

d. To allow detection of spoilage (swelling).

e. To facilitate cartooning.

$\mathrm{f}$. The residual air should be less than $2 \%$ of the volume of the pouch.

Sealing: Hot sealing is perfect to impulse sealing. If impulse sealing is used, it should provide two sides heating and sealing elements should be $6 \mathrm{~mm}$ wide than the normal $3 \mathrm{~mm}$. The pouch should be double sealed to reduce the risk of seal defects. The over seal should extend over the mouth of the pouch to prevent mould growth. Pouch seal must be kept free from other product or even same product to avoid spoilage or resultant leakage.

Metal detector and depressor: Metal detector machine should be placed in line after the pouch filling. The package will be carried out by rotating belt through metal detector. If pouch contain any metal particle then metal detector will separate out that pouch. Metal detector insures that there is no any metal particle inside the pack. It promotes high food safety from physical hazards. Metal detector will be important critical control point in ready to eat vegetables. Metal detector is first CCP in Matar Paneer. Regularly checking of metal detector machine is essential to know that it is working efficiently and continually. After metal detector depressor will be place in line to check pressure bearing capacity of pouch which is also essential to avoid bursting of pouch in sterilization tank.

Serilization/retort: Generally, food is spoiled principally by the action of micro-organisms. Thermal processing destroys harmful micro-organisms by heat. The aim of thermal processing is to bring the food as rapidly as possible to a temperature at which unwanted organisms are killed and to hold the food at temperature long enough to render the food "commercially sterile". Retort processing is the most acceptable form of food preservation. In comparison to frozen food, the retort pouch provides a longer shelf-life and does not require refrigeration, energy expensive methods of distribution and storage. No chemical additives added as most of the bacteria are killed by heat sterilization. Reduction heat exposure results in improvement in taste, colour, flavour and less nutrient loss. Completely destruction of all type of micro-organisms is takes place. Retorting provide the shelf life up 12-18 months. The retort use water and steam combination as processing medium to heat the container/packages. Compressed air or additional steam is introduced during the processing cycle to provide the overpressure (any pressure supplied to the retort in excess of that which can be normally achieved under steam at any given retorts temperature). It is very convenient in handling but should be operate by technical person to avoid losses. After filling and sealing of pouch, those put on the tray and keep the tray inside the container/ autoclave. The temperature inside the container must be $121^{\circ} \mathrm{C}$ with time 25 minutes. After finish the retorting allows the pouches to become cold inside the container for a while and then remove the trays and shift to incubation room.

Overpressure is important in preventing package damage or loss of seal integrity (like bursting), during the heating process. Retorting is the most important "Critical Control Point (CCP)" in ready to eat (Matar Paneer) vegetable because in this process achieving better food safety is take place by killing all micro-organisms.

Incubation: It is a microbial assessment of ready to eat vegetable. After sterilization the product it must be keep in incubation room at room temperature for 4-5 days to check its status and value. Incubation room should be clean, hygienic, and must be free from bad odour. Incubation room is also used for to determine products shelf life. Microbial analysis should be carried out after 4-5 days to assure the food safety. If product found potentially hazardous in microbial analysis then do the corrective action, find out the cause, and determine food handling, hygiene practices and check all process.

Microbial testing: Standard plate count (also referred to as aerobic plate count or total plate count) can provide general information of indication of the microbial quality of food. A standard plate count will not differentiate between the natural micro-flora of food, spoilage microorganisms. It cannot be used to predict the safety of the product and will be influenced by the storage conditions of the product. Depending on the product, a high standard plate count may indicate that the product may have been prepared un-hygienically or stored inappropriately [9].

Indicator organisms: Enterobacteriaceae-Enterobacteriaceae is a group of bacteria that can be found in many environments. In ready to eat foods that are fully cooked, Enterobacteriaceae are used as indication of either post-processing contamination or inadequate cooking. As they can found in raw foods, their detection not is an indication of any processing failure. As such it would be inappropriate to ready to eat foods containing raw components (particularly fresh and vegetables) to Enterobacteriaceae.

Escherichia coli: E. coli presence in ready to eat foods (fully cooked or those containing raw fruits or vegetables) can be an indication of poor hygiene and sanitation or inadequate heat treatment.

Salmonella species: Their presence in ready to eat foods may be result of undercooking, poor handling and cross contamination [10].

Packaging, storage and transport: Packaging is means of providing the correct environmental conditions for food during the length of time it is stored and/or distributed to the consumer. A good package has to perform the following functions:

i. It must keep the product clean and provide a barrier against dirt and other contaminates.

ii. It should prevent losses. Its design should provide protection and convenience in handling, during transport, distribution and marketing. In particular the size, shape and weight of package must be considered. 
iii. It must provide identification and instructions (labeling) so that the food is used correctly and have sales appeal.

iv. It must provide protection to the food against physical and chemical damage (e.g. water and water vapour, oxidation and light) and insects and rodents.

Packaging material for ready to eat vegetables (Matar Paneer), paper packaging is essential. The pouch is inserted in big paper package and then seal. After that the packaged vegetable should be packed in big carton for convenient handling and protection. Different filling machine and packaging machines are available in market. Toyo Jidoki filling machine is ideal for packaging because this machine can open, fill and seal 250 pre-made retort pouches per minute. After properly packaging, store the carton in clean and hygienic room at a room temperature. The place must be free from rodents and insects. Room must have good ventilation and light. Transport the packaged product to retailers and customers. Proper handling and care must be taken while transport to avoid breakage of pouch [11].

Consumer expectations: Ready to eat foods are opening new window in world scenario as far as concerned taste, safety and nutrition. This food do not require rehydration or cooking and can be consumed straight from the pouch with or without pre-warming, depending upon the requirement of user so that it is very time saving and flexible. Matar Paneer fulfills the requirements/expectations of consumer such as, good appearance, colour, flavour and taste. It is highly nutritious. It is totally safe as concern to microbiological aspects. It is easy to cook and use. It is organic and do not consist preservatives or chemical residue. Ready to eat packaged food industry is growing at the rate $20 \%$ per annum, it shows the popularity and consumption and acceptance of ready to eat foods.

\section{Conclusions}

In most of big cities, lifestyles are changing very rapidly. Both husband and wife preferring to work, life has become very fast and preparedness to spend has also gone up. This has resulted in many ready to eat items becoming popular since last few years. Ready to eat vegetable is one such item which is getting popularity in urban areas. After popularity of ready to eat snacks. It is now turn of the food items consumed during meals. Many working couples and their family members have started over to convenience food and ready to eat vegetables etc. Ready to eat food market is developing specifically in UK, USA, Canada, Gulf and South Asian countries with the growth rate over $20 \%$ per annum. To get food of different cultures, taste etc., it is important that food has good shelf life so that it can be made available at far off place too and then can be conveniently consumed also. Organic trends and awareness is increasing in Europe and America. Consumers are become more health conscious. To produce organic product, must use organic raw material. Matar Paneer is nutritious ready to eat vegetable with high quality, taste and flavour. The quality, taste and flavour of ready to eat vegetables remains good as fresh up to expiry date. Good manufacturing practices are very crucial in organic green pea's production. During processing of Matar Paneer basic hygiene is very important to avoid the contamination of harmful microorganisms.
Blanching of green pea provide good texture, taste, flavour and colour to the final product. At cooking and after cooking maintenance of hygiene is essential. Measurement of sensory quality, microbial checking and nutritional checking after cooking is helpful for to update the product and to check the status of product. Retort pouch is the excellent pouch for filling of cooked sauce. It helps to keep safe product in different way and also facilitate the sterilization process. Metal detector is important critical control point to avoid physical hazards. Metal detector detects and out the splinter of metal in pouch during process. Retort processing is the most acceptable form of preservation. Retort is form of thermal processing of food. Food is spoiling principally by the action of micro-organisms. In retort thermal processing destroys these harmful micro-organisms. The application of sterilization technology completely destroys all potentially harmful micro-organisms thereby making sure that the food product has a very long shelf life over 12 months and needed no refrigeration. Sterilization/ Retort are the most essential critical control point. Incubation of pouches after sterilization gives the information of processed product about work done. Most important objective of incubation is to check microbial testing. If any micro-organism found after incubation, it means something going wrong in process or the proper hygiene is did not take place during the production?

The ready to eat (Matar Paneer) is retort processed food, it does not require cooking and can be consumed straight from pouch with or without pre-warming, depending upon the requirement of users and weather conditions. This food meet the consumer's specific expectations like convenience, nutritionally adequate, tasty, microbial safe, colour, flavour, organic and with time saving and easy to use.

\section{References}

1. Robbins C (2013) What is a ready-to-eat food? Livestrong.

2. Mudditt J (2011) Supermarket sob story: Why are imported foods so expensive in Bangladesh?

3. Convenience food (2012) Convenience food products.

4. NYS IPM (2013) Production guide for organic peas for processing. NYS IPM Publication.

5. NYS IPM (2012) Production guide for organic peas for processing. NYS IPM Publication.

6. Antorino L, Weinberger K (2010) Vegetable post harvest. AVRDC and GIZ Publication.

7. Birader GS, Gujar SK, Dande KG, Gaikwad SM (2012) Studies on physiochemical quality of paneer prepared from blends of soymilk and buffalo milk. $J$ Anim Prod Adv 2: 142-145.

8. James IF, Kupier P (2003) Preservation of fruits and vegetables, microbiological quality guide for ready-to-eat foods, Micro-ovenable packages and retortable package, Agromisa foundation, Wageningen.

9. Sagoo SK, Little CL, Mitchell RT (2001) The microbiological examination of ready-to-eat organic vegetables from retail establishments in the United Kingdom.

10. Rudrappa U (2009) Nutrition and You

11. IDS (2002) Retort flexible packaging. 